\title{
DETERMINANTS OF NEONATAL MORTALITY BASED ON THE 2017 INDONESIAN DEMOGRAPHIC AND HEALTH SURVEY (IDHS)
}

\author{
Fidya Rumiati' ${ }^{1}$ Asri C. Adisasmita ${ }^{2}$ \\ ${ }^{1}$ Masters in Epidemiology, Faculty of Public Health, Indonesia University, Jakarta, Indonesia \\ ${ }^{2}$ Department of Epidemiology, Faculty of Public Health, University, Jakarta, Indonesia \\ Correspondence: Fidya Rumiati \\ E-mail: fidya.rumiati@ui.ac.id
}

\begin{abstract}
Infant mortality is still a major health problem in Indonesia as $63 \%$ of deaths occur in the neonatal period. The trend of the neonatal mortality rate in Indonesia has decreased from 15 (2017) to 13 deaths per 1,000 live births (2018), but this does not meet the Sustainable Development Goals (SDGs) target. Evidence-based health interventions are based on determinants that most influences neonatal mortality. The purpose of this study was to determine the most influential determinants of neonatal mortality in Indonesia. This research is an analytic observational study that uses the 2017 Indonesian Demographic and Health Survey (IDHS) data, with a crosssectional design. This study's population was the last baby of married women of childbearing age (15-49 years) and was recorded in the 2017 IDHS with a sample of 15,102 babies. The outcome variable in this study was neonatal mortality. The analysis was conducted in stages, namely univariate analysis, bivariate analysis using the chi-square statistical test (X2), and multivariate analysis using logistic regression. The results showed that $85.71 \%$ of deaths occurred in the early neonatal period. The most influential determinants of neonatal mortality were male sex $(\operatorname{adj} O R=2.91: 95 \%$ CI 1.78-4.76), low birth weight $(\operatorname{adj} O R=12.08: 95 \%$ CI 7.38-18.86) and parity status $\geq 4$ (adj OR $=2.11: 95 \%$ CI 1.22-3.61). Public health interventions aimed at reducing neonatal mortality should be linked to newborn and maternal characteristics that significantly influence Indonesia's neonatal mortality. Therefore, health services must consider adequate postpartum neonatal care that is fully integrated with medical care. Moreover, further prevention of potential factors that cause low birth weight before conception should be implemented and further control of births would optimize the family planning program.
\end{abstract}

Keywords: gender, low birth weight, parity status, determinant, neonatal mortality, Indonesia

\section{INTRODUCTION}

The infant mortality rate (IMR) around the world is still high. Globally, in $2019,85 \%$ or the equivalent of 5.3 million deaths occurred for infants under the age of five. Based on this number, as much as 2.5 million deaths $(7,000$ deaths per day) or $47 \%$ of infant deaths occurred during the neonatal period. Conversely, there has been a faster reduction in global mortality among children aged 1-59 months compared with children in their first month of life (UNICEF, 2018). Therefore, reducing the mortality rate in the neonatal period can significantly reduce the infant mortality rate. Globally, of all known neonatal deaths, $98 \%$ of deaths occur in developing countries (WHO, 2006). Neonatal mortality is defined as death in the first month of life (0-28 days of age). This first month is the most crucial period for the child's survival because the risk of neonatal mortality is up to 50 times greater in countries with the highest mortality compared to countries with low mortality (UNICEF, 2018).

Over the past 30 years, the decline in neonatal mortality has been slower than that for children under five and children after the first month of life (Hill and Choi, 2006). The largest decline from 1990 to 2018 occurred in East Asia (84\%). Furthermore, the burden of neonatal mortality is uneven, as indicated by the high mortality rate in other SDGs areas. SubSaharan Africa had the highest neonatal mortality rate in 2018 , with 28 deaths per 1,000 live births, followed by Central and South Asia with 25 deaths per 1,000 live births. In Southeast Asia alone, the neonatal mortality rate is 13 deaths per 1,000 live births, with the highest neonatal mortality rates being in Myanmar and Laos (23 deaths per 1,000 live births) (UNICEF, 2019). In 2012-2017, 63\% of infant mortality in Indonesia occurred in the 
neonatal period. The neonatal mortality rate in Indonesia has decreased from 15 deaths per 1,000 live births in 2017 (Ministry of Health RI, 2018) to 13 deaths per 1,000 live births in 2018 (WHO, 2020).

Given the current high infant mortality rate, child survival remains an urgent concern for many countries. Mortality rates for children under-five around the world is dominated by newborn mortality. Most of these are caused by the baby's condition and diseases related to the lack of quality and skilled delivery care and prompt postpartum care. Several factors drive the high rate of neonatal mortality in the world. The WHO estimates that the causes of neonatal mortality in the world in 2018 are complications of preterm birth (35\%), intrapartum complications (24\%), sepsis (15\%), congenital abnormalities (11\%), pneumonia, tetanus, diarrhea ( $8 \%$ ), and others (7\%) (UNICEF: WHO: World Bank: UN DESA, 2019). In Indonesia, neonatal mortality is mainly caused by complications of preterm birth (35\%), intrapartum complications (23\%), sepsis and tetanus (12\%), and congenital abnormalities (18\%) (UNICEF, 2016). These factorsa tend to be medical and lead directly to death in the neonatal period.

Mosley and Chen (2003) described the conceptual framework of child survival in developing countries. Apart from direct causative factors, social and economic determinants are proxy determinants that affect child mortality through biological mechanisms and impact child mortality. The determinants are divided into five groups: maternal factors (age, parity, birth spacing), environment, nutritional deficiencies, accidents, and personal health measures (curative and preventive). This study aims to determine the determinants of neonatal mortality based on the analysis of the 2017 IDHS data. Determining the causes of neonatal mortality is important as it could guide the development of evidencebased health interventions and prevent neonatal mortality.

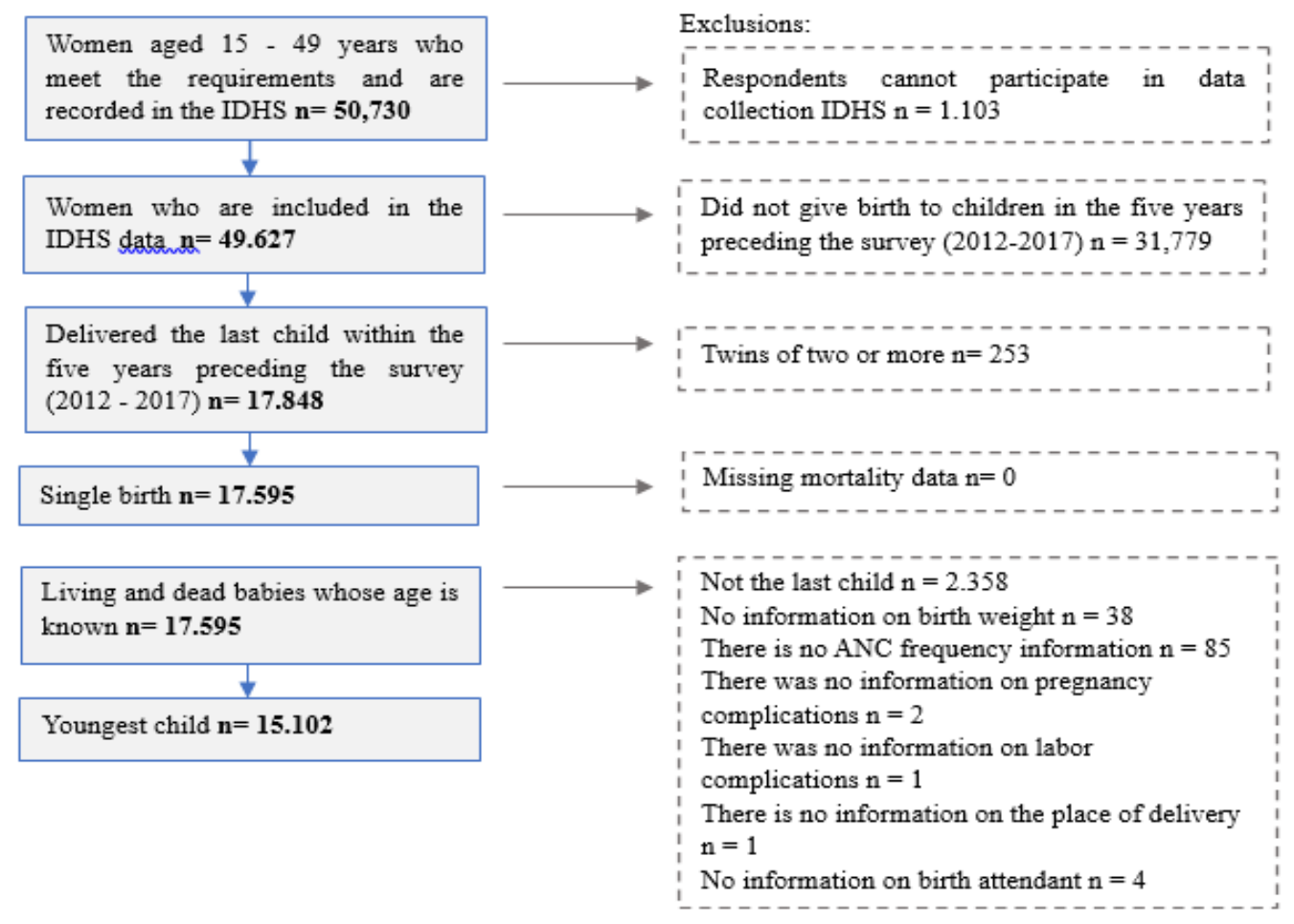

Figure 1. Sample Selection Framework 


\section{METHOD}

This research is an analytic observational study with a cross-sectional design. The research used data from the 2017 Indonesian Demographic and Health Survey (IDHS). The IDHS is part of the international DHS program through the measure of DHS project. The Indonesian Central Statistics Agency conducted the survey, along with the National Population and Family Planning Agency, and the Ministry of Health with the support of ICF International. The most recent survey conducted in Indonesia took place from July 24 to September 30, 2017. The DHS sampling design is a two-stage cluster design. The sample frame uses the master census block sample from the 2010 population census. In this study, only information from the women's questionnaire was used.

This study's outcome variable was neonatal mortality, defined as death occurring at $0-28$ days after birth (WHO, 2006). The independent variables are grouped into four, namely infant factors (baby's sex and birth weight), maternal factors (maternal age at delivery, parity, birth spacing, pregnancy complications, labor complications, and stillbirth history), health service utility, (frequency of antenatal care visits, assistant's lowest qualification and place of delivery) and socio-economic factors (place of residence, mother's education, household wealth index, and health insurance ownership).

The eligible population is the last infant of married women of reproductive age (15 - 49 years) who are recorded in the 2017 IDHS $(\mathrm{n}=17,848)$. This study's population met the inclusion criteria (mothers who gave birth to their last child within five years before the survey) and exclusion criteria (multiple births and unknown age of the baby at death). The analysis was conducted after the missing data for each variable was removed, thus a sample of 15,102 was obtained as this study's population.
The DHS survey used a complex sampling design with the cluster method, therefore the data analysis needed to consider the design effect and weight. The design effect compares the variance obtained, while the weight is the calculation of the total population of an area divided by the number of samples taken in that area, by considering these aspects, this allows the analysis to be conducted with a complex sample. Analysis without weighting will give incorrect results because the number of the population and the number of samples selected in each cluster needed to determine the sample's probability is not the same. The analysis was conducted in stages, namely univariate analysis to get an overview of the frequency distribution, bivariate analysis using the Chi-Square (X2) statistical test, and multivariate analysis using Logistic Regression, which will produce OR for the case-control design, but as the incident (neonatal death) in this study is rare $(<10 \%)$, the OR will reflect the results of the RR, so it will not provide an overestimate result (Gordis, 2014).

The data used has received approval from the ICF International Demographic Health Survey through the Measure DHS International page. This IDHS follows the Standard DHS protocol number DHS-7. Ethical permission from the IDHS has been obtained from the ICF InternationalInstitutional Review Board (ICF IRB FWA00000845) with the number: 132989.0.000 and complies with the requirements of the United States Department of Health and Human Services on "Protection of Human Subjects" (45 CFR 46).

\section{RESULTS}

In the five years before the survey's implementation in 2017, 15,102 single live births met the inclusion and exclusion criteria. The majority of neonatal mortality in Indonesia occurs in the early neonatal period, with a percentage of $85.71 \%$; this 
figure is substantial compared to the percentage of deaths in the late neonatal period at $14.29 \%$.

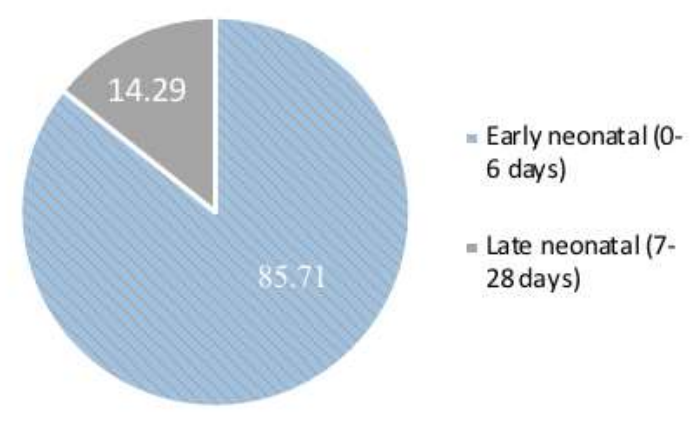

Figure 2. Diagram of Neonatal Period Mortality in Indonesia

Table 1 shows the frequency distribution and characteristics of each variable after weighting. Based on Table 1 , for the dependent variable neonates, the proportion of them who survived was $99.18 \%$, while those who died were $0.82 \%$. For the independent variable with weighting, it can be seen that the majority of neonates are male $(51.17 \%)$. Most of the neonates that were surveyed were born with normal birth weight, namely $\geq 2,500$ grams $(89.50 \%)$. The majority of maternal age at delivery was $20-35$ years $(76.69 \%)$, and $53.45 \%$ had 2-3 parity status. The distance between neonatal births and previous children was mostly $\geq 36$ months $(87.24 \%)$. Most mothers also wanted their pregnancy at that time $(83.7 \%)$, and most mothers did not have a history of stillbirth $(85.68 \%)$. However, the incidence of pregnancy complications $(68.74 \%)$ and childbirth $(71.23 \%)$ of mothers are still relatively high. It can also be seen that the frequency of antenatal care visits being $\geq 4$ times has reached $91.23 \%$. Midwives were the most preferred birth attendants (46.45\%) than other birth attendants, and most deliveries were carried out in private practice places $(32.46 \%)$. More than half of mothers already have health insurance $(58.76 \%)$. Most of the mother's highest education is a high school (58.38\%) and they live almost evenly at every level of the wealth quintile; there were also more mothers who live in urban areas $(68.56 \%)$ as compared to mothers who live in rural areas $(51.44 \%)$.

Table 2 shows that male babies are more at risk of neonatal mortality than females $(\mathrm{OR}=2.16$ : 95\% CI 1.47-3.19). When comparing birth weights of $<2,500$ grams (low birth weight) versus birth weights of $\geq 2,500$ grams, it could be seen that birth weight was significant to neonatal mortality $(\mathrm{OR}=12.19: 95 \%$ CI 7.88-18, 85). Furthermore, mothers with a birth spacing of $<18$ months have 4 times the risk of neonatal mortality than mothers with 2435 months of birth spacing, and this factor proved to be significant. A maternal age that is too young when giving birth also contributes to risk for neonatal mortality. However, it was not significantly proven $(\mathrm{OR}=1.12: 95 \%$ CI 0.57-2.23), whereas age $>35$ years at delivery had a 2.66 times higher risk $(\mathrm{OR}=2.49$ : 95\% CI 1.80-3.95) for the incidence of neonatal mortality compared to ages 20-35 years, and this factor proved to be significant. Additionally, the parity status of mothers who gave birth once tended to be more protective against neonatal mortality $(\mathrm{OR}=$ 0.71: 95\% CI 0.45-1.12), but mothers with a history of childbirth of $\geq 4$ times had a higher risk of neonatal death, and this factor proved to be significant $(\mathrm{OR}=2.22$ : $95 \%$ CI 1.45-3.40). Mothers who only had antenatal care (ANC) visits 1-3 times had a greater risk of neonatal death than mothers who had $\geq 4$ ANC visits (OR $=2.38: 95 \%$ CI 1.40-4.04).

The risk of neonatal death from birth attendants appeared positive in all categories but did not show a dose-response relationship, nor did the variable of the maternal place of delivery. Mothers who have never attended school have a risk of neonatal mortality 3.02 times greater that of mothers who have attended tertiary education, but this result is not significant. The greatest threat came from very poor households $(\mathrm{OR}=1.77$ : 95\% CI 0.99-3.16), but this was also not significantly proven. 
The multivariate analysis (Table 3) showed that the variables that are determinants of neonatal mortality in the final model are the sex of the baby, birth weight, parity, and place of delivery. There is no significant change between the adjusted OR value and the crude OR value. For the delivery variable, the adjusted OR value obtained indicates that there is no dose-response relationship in each category between delivery at a health facility and delivery at home.

Table 1. Characteristics of Respondents (Weighted)

\begin{tabular}{|c|c|c|}
\hline Variables & $\mathbf{n}$ & $\%$ \\
\hline \multicolumn{3}{|l|}{ Neonatal Deaths } \\
\hline Stay alive & 14.675 & 99.18 \\
\hline Die & 121 & 0.82 \\
\hline \multicolumn{3}{|l|}{ Infant Factor } \\
\hline \multicolumn{3}{|l|}{ Gender } \\
\hline Male & 7.571 & 51.17 \\
\hline Female & 7.226 & 48.83 \\
\hline \multicolumn{3}{|l|}{ Birth Weight } \\
\hline$\geq 2.50$ grams & 13.243 & 89.50 \\
\hline$<2.50$ grams & 893 & 6.04 \\
\hline Not weighed & 660 & 4.46 \\
\hline \multicolumn{3}{|l|}{ Maternal Factors } \\
\hline \multicolumn{3}{|l|}{ Birth Interval } \\
\hline$<18$ months & 322 & 2.18 \\
\hline $18-23$ months & 460 & 3.11 \\
\hline Variables & $\mathbf{n}$ & $\%$ \\
\hline $24-35$ months & 1.106 & 7.47 \\
\hline$\geq 36$ months & 12.908 & 87.24 \\
\hline \multicolumn{3}{|l|}{ Maternal Age at Childbirth } \\
\hline$<20$ years & 1.264 & 8.55 \\
\hline $20-35$ years & 11.348 & 76.69 \\
\hline$\geq 36$ years & 2.184 & 14.76 \\
\hline \multicolumn{3}{|l|}{ Parity } \\
\hline 1 & 4.974 & 33.62 \\
\hline $2-3$ & 7.909 & 53.45 \\
\hline$\geq 4$ & 1.913 & 12.93 \\
\hline \multicolumn{3}{|l|}{ Pregnancy Desires } \\
\hline Wanted urge & 12.395 & 83.77 \\
\hline Wanted later & 1.199 & 8.11 \\
\hline Wanted no more & 1.202 & 8.13 \\
\hline \multicolumn{3}{|l|}{ Pregnancy Complications } \\
\hline No & 4.625 & 31.26 \\
\hline Yes & 10.171 & 68.74 \\
\hline \multicolumn{3}{|l|}{ History of Stillbirth } \\
\hline No & 12.677 & 85.68 \\
\hline Yes & 2.119 & 14.32 \\
\hline \multicolumn{3}{|l|}{ ANC Visit Frequency } \\
\hline $1-3$ times & 942 & 6.37 \\
\hline$\geq 4$ times & 13.500 & 91.23 \\
\hline Never & 355 & 2.40 \\
\hline
\end{tabular}




\begin{tabular}{|c|c|c|}
\hline $\begin{array}{l}\text { Variables } \\
\end{array}$ & $\mathbf{n}$ & $\%$ \\
\hline \multicolumn{3}{|l|}{ Labor Complications } \\
\hline No & 4.257 & 28.77 \\
\hline Yes & 10.539 & 71.23 \\
\hline \multicolumn{3}{|l|}{ Delivery Assistants } \\
\hline Doctor & 1.468 & 9.92 \\
\hline Midwife & 6.874 & 46.45 \\
\hline Nurse & 3.151 & 21.30 \\
\hline Traditional birth attendant & 1.445 & 9.77 \\
\hline Family/friends & 1.858 & 12.56 \\
\hline \multicolumn{3}{|l|}{ Utilization of Health Services } \\
\hline \multicolumn{3}{|l|}{ Place of Delivery } \\
\hline Hospital & 4.701 & 31.77 \\
\hline Primary healthcare center & 1.372 & 9.28 \\
\hline Clinic & 1.060 & 7.16 \\
\hline Private practice & 4.803 & 32.46 \\
\hline Home & 2.859 & 19.33 \\
\hline \multicolumn{3}{|l|}{ Mother's Education } \\
\hline Higher & 2.180 & 14.73 \\
\hline Secondary & 8.638 & 58.38 \\
\hline Primary & 3.834 & 25.91 \\
\hline No education & 144 & 0.98 \\
\hline \multicolumn{3}{|l|}{ Socio-demographic Factors } \\
\hline \multicolumn{3}{|l|}{ Wealth Index } \\
\hline Richest & 2.801 & 18.93 \\
\hline Rich & 3.036 & 20.52 \\
\hline Variables & $\mathbf{n}$ & $\%$ \\
\hline Middle-Income & 3.055 & 20.65 \\
\hline Poor & 2.983 & 20.16 \\
\hline Poorest & 2.920 & 19.74 \\
\hline \multicolumn{3}{|l|}{ Health Insurance Ownership } \\
\hline Yes & 8.694 & 58.76 \\
\hline No & 6.103 & 41.24 \\
\hline \multicolumn{3}{|l|}{ Residence } \\
\hline Urban & 7.186 & 68.56 \\
\hline Rural & 7.611 & 51.44 \\
\hline
\end{tabular}

Table 2. Bivariate Analysis of Independent Variables on Neonatal Mortality in Indonesia (Weighted)

\begin{tabular}{|c|c|c|c|c|c|c|c|}
\hline \multirow{3}{*}{ Variables } & \multicolumn{4}{|c|}{ Neonatal } & \multirow{3}{*}{$\begin{array}{c}\text { Crude } \\
\text { OR }\end{array}$} & \multirow{3}{*}{$95 \%$ CI } & \multirow{3}{*}{ p-value } \\
\hline & \multicolumn{2}{|c|}{ Alive } & \multicolumn{2}{|c|}{ Dead } & & & \\
\hline & $\mathbf{n}$ & $\%$ & $\mathbf{n}$ & $\%$ & & & \\
\hline \multicolumn{8}{|l|}{ Infant Factor } \\
\hline \multicolumn{8}{|l|}{ Gender } \\
\hline Male & 7.486 & 98.88 & 84 & 1.12 & 2.16 & $1.47-3.19$ & 0.000 \\
\hline Female & 7.188 & 99.48 & 37 & 0.52 & $R e f$ & & - \\
\hline \multicolumn{8}{|l|}{ Birth Weight } \\
\hline$\geq 2.50$ grams & 13.196 & 99.65 & 46 & 0.35 & Ref & - & - \\
\hline$<2.50$ grams & 856 & 95.84 & 37 & 4.16 & 12.19 & $7.88-18.85$ & 0.000 \\
\hline
\end{tabular}




\begin{tabular}{|c|c|c|c|c|c|c|c|}
\hline \multirow{3}{*}{ Variables } & \multicolumn{4}{|c|}{ Neonatal } & \multirow{3}{*}{$\begin{array}{l}\text { Crude } \\
\text { OR }\end{array}$} & \multirow{3}{*}{$95 \% \mathrm{CI}$} & \multirow{3}{*}{ p-value } \\
\hline & \multicolumn{2}{|c|}{ Alive } & \multicolumn{2}{|c|}{ Dead } & & & \\
\hline & $\mathrm{n}$ & $\%$ & $\mathbf{n}$ & $\%$ & & & \\
\hline Not weighed & 622 & 94.27 & 37 & 5.73 & 17.07 & $11.04-26.40$ & 0.000 \\
\hline \multicolumn{8}{|l|}{ Birth Interval } \\
\hline$<18$ months & 314 & 97.73 & 7 & 2.27 & 4.00 & $1.37-11.64$ & 0.011 \\
\hline $18-23$ months & 457 & 99.30 & 3 & 0.70 & 1.21 & $0.31-4.65$ & 0.773 \\
\hline $24-35$ months & 1.099 & 99.42 & 6 & 0.58 & Ref & - & - \\
\hline$\geq 36$ months & 12.803 & 99.19 & 104 & 0.81 & 1.40 & $0.63-3.13$ & 0.400 \\
\hline \multicolumn{8}{|c|}{ Maternal Factors } \\
\hline \multicolumn{8}{|c|}{$\begin{array}{l}\text { Maternal Age at } \\
\text { Childbirth }\end{array}$} \\
\hline$<20$ years & 1.255 & 99.26 & 9 & 0.74 & 1.12 & $0.57-2.23$ & 0.727 \\
\hline $20-35$ years & 11.273 & 99.34 & 74 & 0.66 & Ref & - & - \\
\hline$>35$ years & 2.146 & 98.26 & 37 & 1.74 & 2.66 & $1.80-3.95$ & 0.000 \\
\hline \multicolumn{8}{|l|}{ Parity } \\
\hline 1 & 4.946 & 99.44 & 27 & 0.56 & 0.71 & $0.45-1.12$ & 0.151 \\
\hline $2-3$ & 7.847 & 99.22 & 61 & 0.78 & Ref & - & - \\
\hline$\geq 4$ & 1.880 & 98.18 & 32 & 1.71 & 2.22 & $1.45-3.40$ & 0.00 \\
\hline \multicolumn{8}{|l|}{ Pregnant Desires } \\
\hline Wanted urge & 12.292 & 99.17 & 102 & 0.83 & Ref & - & - \\
\hline Wanted later & 1.194 & 99.55 & 5 & 0.45 & 0.54 & $0.22-1.28$ & 0.166 \\
\hline Wanted no more & 1.189 & 98.87 & 13 & 1.13 & 1.36 & $0.76-2.40$ & 0.289 \\
\hline \multicolumn{8}{|l|}{$\begin{array}{l}\text { Pregnancy } \\
\text { Complications }\end{array}$} \\
\hline No & 4.576 & 98.93 & 49 & 1.07 & Ref & - & - \\
\hline Yes & 10,099 & 99.29 & 72 & 0.71 & 0.66 & $0.45-0.94$ & 0.025 \\
\hline \multicolumn{8}{|c|}{ History of Stillbirth } \\
\hline No & 12.570 & 99.15 & 107 & 0.85 & Ref & - & - \\
\hline Yes & 2.105 & 99.32 & 14 & 0.68 & 0.79 & $0.45-1.28$ & 0.422 \\
\hline \multicolumn{8}{|l|}{$\begin{array}{l}\text { ANC Visit } \\
\text { Frequency }\end{array}$} \\
\hline $1-3$ times & 925 & 98.28 & 16 & 1.72 & 2.38 & $1.40-4.04$ & 0.001 \\
\hline$\geq 4$ times & 13.401 & 99.27 & 98 & 0.73 & $\operatorname{Ref}$ & - & - \\
\hline Never & 347 & 97.89 & 7 & 2.11 & 2.9 & $1.38-6.2$ & 0.005 \\
\hline \multicolumn{8}{|l|}{$\begin{array}{l}\text { Labor } \\
\text { Complications }\end{array}$} \\
\hline No & 4.223 & 99.19 & 34 & 0.81 & Ref & - & - \\
\hline Yes & 10.452 & 99.17 & 87 & 0.83 & 1.02 & $0.69-1.52$ & 0.891 \\
\hline \multicolumn{8}{|c|}{ Childbirth Helper } \\
\hline Doctor & 1.450 & 98.78 & 17 & 1.22 & Ref & - & - \\
\hline Midwife & 6.824 & 99.28 & 49 & 0.72 & 0.58 & $0.33-1.00$ & 0.052 \\
\hline Nurse & 3.112 & 99.10 & 28 & 0.90 & 0.73 & $0.40-1.32$ & 0.303 \\
\hline $\begin{array}{l}\text { Traditional birth } \\
\text { attendant }\end{array}$ & 1.430 & 98.97 & 14 & 1.03 & 0.83 & $0.41-1.67$ & 0.613 \\
\hline Family / friends & 1.846 & 99.38 & 11 & 0.62 & 0.50 & $0.23-1.05$ & 0.070 \\
\hline
\end{tabular}




\begin{tabular}{|c|c|c|c|c|c|c|c|}
\hline \multirow{3}{*}{ Variables } & \multicolumn{4}{|c|}{ Neonatal } & \multirow{3}{*}{$\begin{array}{c}\text { Crude } \\
\text { OR }\end{array}$} & \multirow{3}{*}{$95 \%$ CI } & \multirow{3}{*}{ p-value } \\
\hline & \multicolumn{2}{|c|}{ Alive } & \multicolumn{2}{|c|}{ Dead } & & & \\
\hline & n & $\%$ & $\mathrm{n}$ & $\%$ & & & \\
\hline \multicolumn{8}{|l|}{ Place of Delivery } \\
\hline Hospital & 4.648 & 98.88 & 52 & 1.12 & Ref & - & - \\
\hline $\begin{array}{l}\text { Primary healthcare } \\
\text { center }\end{array}$ & 1.365 & 99.48 & 7 & 0.52 & 0.45 & $0.20-1.00$ & 0.018 \\
\hline Clinic & 1.052 & 99.24 & 8 & 0.76 & 0.67 & $0.32-1.41$ & 0.749 \\
\hline Private practice & 4.779 & 99.50 & 24 & 0.50 & 0.44 & $0.27-0.72$ & 0.001 \\
\hline House & 2.829 & 98.96 & 29 & 1.04 & 0.92 & $0.58-1.45$ & 0.732 \\
\hline \multicolumn{8}{|l|}{ Mother's Education } \\
\hline Higher & 2.165 & 99.32 & 14 & 0.68 & Ref & - & - \\
\hline Secondary & 8.576 & 99.28 & 62 & 0.72 & 1.06 & $0.60-1.87$ & 0.839 \\
\hline Primary & 3.791 & 98.90 & 42 & 1.10 & 1.62 & $0.89-2.95$ & 0.107 \\
\hline No education & 142 & 97.97 & 2 & 2.03 & 3.02 & $0.85-10.72$ & 0.086 \\
\hline \multicolumn{8}{|l|}{$\begin{array}{l}\text { Socio-demographic } \\
\text { Factors }\end{array}$} \\
\hline \multicolumn{8}{|l|}{ Wealth Index } \\
\hline Richest & 2.783 & 99.36 & 17 & 0.64 & Ref & - & - \\
\hline Richer & 3.003 & 98.91 & 33 & 1.09 & 1.72 & $0.96-3.07$ & 0.065 \\
\hline Middle & 3.038 & 99.44 & 16 & 0.56 & 0.87 & $0.44-1.69$ & 0.687 \\
\hline Poorer & 2.962 & 99.30 & 21 & 0.70 & 1.10 & $0.58-2.08$ & 0.755 \\
\hline Poorest & 2.887 & 98.87 & 32 & 1.13 & 1.77 & $0.99-3.16$ & 0.052 \\
\hline \multicolumn{8}{|l|}{$\begin{array}{l}\text { Health Insurance } \\
\text { Ownership }\end{array}$} \\
\hline Yes & 8.614 & 99.07 & 80 & 0.93 & Ref & - & - \\
\hline No & 6.061 & 99.32 & 41 & 0.68 & 0.73 & $0.50-1.06$ & 0.105 \\
\hline \multicolumn{8}{|l|}{ Residence } \\
\hline Urban & 7122 & 99.12 & 63 & 0.88 & Ref & - & - \\
\hline Rural & 7.552 & 99.23 & 58 & 0.77 & 0.87 & $0.61-1.25$ & 0.467 \\
\hline
\end{tabular}

Crude variables

Table 3. Final Model of Multivariate Analysis of Independent Variables on Neonatal Mortality in Indonesia (Weighted)

\begin{tabular}{lcccc}
\hline \multicolumn{1}{c}{ Variables } & Crude OR & Adjusted OR & 95 \% CI & p-value \\
\hline Infant Factor & & & & \\
Gender & & & & \\
Female & Ref & Ref & - & - \\
Male & 2.16 & 2.91 & $1.78-4.76$ & 0.000 \\
\hline Birth Weight & & & & \\
$\geq 2.50$ grams & Ref & Ref & - & - \\
$<2.50$ grams & 12.19 & 12.08 & $7.74-18.86$ & 0.000 \\
\hline Maternal Factors & & & & \\
Parity & & & & \\
1 & 0.71 & 0.55 & $0.31-0.95$ & 0.032 \\
$2-3$ & $R e f$ & $R e f$ & - & - \\
$\geq 4$ & 2.22 & 2.11 & $1.22-3.61$ & 0.006 \\
\hline
\end{tabular}

\section{Utilization of Health}




\begin{tabular}{lcccc}
\hline Services & & & & \\
Place of Delivery & & & & \\
Hospital & Ref & Ref & - & - \\
Primary healthcare center & 0.45 & 0.50 & $0.21-1.15$ & 0.042 \\
Clinic & 0.67 & 0.58 & $0.23-1.44$ & 0.622 \\
Private practice & 0.44 & 0.41 & $0.23-0.74$ & 0.003 \\
Home & 0.92 & 0.42 & $0.21-0.84$ & 0.017 \\
\hline
\end{tabular}

Adjusted variables

\section{DISCUSSION}

In the multivariate analysis, the factors that affect neonatal mortality in Indonesia are gender and birth weight. Infants of the male sex had a higher risk of neonatal mortality (adj OR $=2.91: 95 \% \mathrm{CI}$ $1.78-4.76$ ), and this was significantly proven. Not only in Indonesia, but the results of a study in Bangladesh also showed that the chance for neonatal death was substantially higher among the newborn male sex (adj OR: 1.5, 95\% CI: 1.2-1.8) (Al Kibria et al., 2018); similar results were also found in a study that used DHS data in Nigeria in 2013 (adj OR, 1.67; 95\% CI: 1.22-2.28) (Adewuyi and Zhao, 2017).

The greater risk of neonatal death in male sex babies can be explained by the differences in genetic makeup for males and females (Pongou, 2013). The effect of sex hormones on the balance of T-helper 1 or T-helper 2 cytokines explains the higher severity of some infectious diseases in men compared to women. Women are known to have more robust humoral and cellular immune responses to infection or antigenic stimulation than men (Muenchhoff and

One of the maternal factors that determine neonatal mortality is parity. The majority of maternal parity in this study were 2 - 3 times (multiparous), namely $53.45 \%$. For their first birth experience, mothers tended to be protective for neonatal mortality (adj OR $=0.54: 95 \%$ CI 0.31 0.94); this may be because the mother's age at birth of her first child was at a safe age. Meanwhile, mothers who had given birth to children $\geq 4$ times had a 2.14 times greater risk than mothers who had given birth to
Goulder, 2014). Although boys have a greater risk of neonatal death, it is difficult to intervene in the sex of the child to be born.

Next, birth weight has a massive effect on neonatal mortality; Indonesia's percentage of babies born with low birth weight is $6.29 \%$. Babies born with low birth weight have a 12.24 times greater risk of neonatal death than babies with normal birth weight ( $\geq 2.50$ grams). Infants with low birth weights has a higher risk for late growth and development, is more susceptible to infectious diseases, and has a higher risk for death in the early period of life. These results are in line with the research of Oakley et al. (2009) who found that infants with low birth weight had a 7.38 times higher risk of death than those of normal birth weight in the UK (adj OR = 7.38: $95 \%$ CI 6.80-8.00). In theory, maternal gestational age is related to the endurance of the newborn. Still, gestational age is not available in the IDHS data, so this study could not determine whether babies with low birth weight do not have a fullterm gestational age or if it was due to other causes during the gestation term.

children 2 - 3 times (adj OR $=2.14: 95 \% \mathrm{CI}$ 1.25-3.66). Research in New South Wales showed the same results. Grouping parity levels into nulliparity, low multiparity (parity 1, 2, and 3), and grand multiparity (parity 4-8) showed a significant association with obstetric complications, neonatal morbidity, and perinatal mortality. The risk of perinatal death was also significantly higher in the nulliparous group and parity $\geq 4$, with the highest risk 
at parity 7 and $8(\operatorname{adj} \mathrm{OR}=2.89: 95 \% \mathrm{CI}$ 1.86-4.50) (Bai et al., 2002).

Women who have given birth to four or more babies with a gestational age of more than 20 weeks (grand multipara) can be at risk for stillbirths, babies born with low birth weight, preterm birth, and perinatal death (Malhotra et al., 2014). Every pregnancy that is followed by repeated delivery will cause changes in the uterus. The changing conditions of the uterus can be aggravated by the pregnancy being too short, as it causes damage to the blood vessels and affects the fetus' circulation of nutrients. The amount of nutrients the fetus gets will be reduced in mothers with pregnancy that are too short compared to previous pregnancies, and this will cause fetal growth disorders (Prawirohardjo, 2008).

The results of the multivariate analysis of this study indicate that all categories in the place of delivery variable tend to show a positive relationship compared to hospital deliveries regarding the incidence of neonatal mortality in Indonesia. This positive relationship is seen for both deliveries at health facilities, especially in private practice places, (adj $\mathrm{OR}=0.41: 95 \%$ CI $0.23-0.74)$ and nonhealth facilities such as delivery at home $(\operatorname{adj} \mathrm{OR}=0.42: 95 \%$ CI 0.21-0.84). This may be because the mother had previously received treatment from a first or secondlevel health facility or a non-health facility and was eventually referred to the hospital as a high-level health facility due to

Moreover, the bias that can occur in this study is information bias because the IDHS comes from interviews with women of childbearing age and is very dependent on memory (recall). There is the possibility that the mother cannot remember with certainty the answers to the questions asked, such as the variables of birthweight, pregnancy complications, delivery complications, and frequency of antenatal care visits, which can lead to nondifferential information bias. Errors in the deteriorating health conditions and increased neonatal risk of death. Likewise, with the birth attendant variable in table 2, deliveries with families tended to be positive compared to doctors. This can be because childbirth with a doctor is used as a last resort to assist in delivery when it is felt that a lower qualified birth attendant cannot help the mother's condition.

Delivery in a hospital with a doctor is the safest option, therefore it is one of the critical elements in reducing maternal and neonatal mortality. Thus, it is crucial to ensure that the mother will give birth in a suitable place. A place of delivery with lifesaving equipment and hygienic delivery conditions can help mothers and babies avoid the risk of complications that can cause illness and death, especially in the first period of life (Kesterton et al., 2010).

A limitation of the cross-sectional study design is its inability to prove a causal relationship. The temporal relationship can be ascertained because the exposure status in this study occurred before the outcome (neonatal death). The variable of post-natal examination of infants, in theory, affects neonatal mortality available in the data; however, there is a large amount of missing data in this variable $(33.23 \%)$ such that it was not included in the study. This is because the baby has died before post-natal services could be provided. There are $63.19 \%$ of babies that died on the first day after birth. Based on the missing post-natal examination variables, it is known that $67.12 \%$ of them are neonatal deaths occur on the first day after delivery.

mother's answer can cause the results to not describe the actual conditions of when the neonatal death occurred. Besides, the data only comes from women who were still alive at the time of the survey, so the number of neonatal deaths that is obtained would be lower than the actual number.

Based on this survey results, there is a large amount of missing data, which can cause the available data to be unrepresentative, and lead to selection bias. The proportion of missing data in each 
variable included in this study was small $(<10 \%)$ and was excluded before analysis to avoid selection bias. In the multivariate analysis, it is known that the confidence interval is quite wide in the variable of birth weight, this may be due to the small population in each table cell. Nevertheless, this study's results can be generalized to the population in Indonesia because the sample selection was conducted in each province.

\section{CONCLUSION}

The most dominant determinants in the incidence of neonatal mortality in Indonesia based on the 2017 IDHS data are infant and maternal factors. These results are in accordance with previous theory and research. Male babies are more prone to die in the neonatal period along with babies with low birth weight, and babies born to mothers with a parity of $\geq 4$. Intervention efforts for the sex of the child to be born are quite challenging to implement because biologically male children are weaker and prone to disease and death in the neonatal period. However, prevention efforts can still be made to maternal factors. It is known that the mother's health condition has a significant influence on infant factors in the incidence of neonatal mortality and supporting infant health can be done by optimizing baby examinations as early as possible after birth.

Improvements in nutrition and preparation for maternal health during pregnancy must be made before the conception period. Nutritional supplementation during pregnancy is done to prevent mothers from chronic energy deficiency and lower the risk of giving birth to children with low birth weight. The contribution of infants with low birth weight to neonatal mortality is very high. Therefore, it is necessary to monitor the fetus's growth in the womb during pregnancy and provide appropriate nutritional support services for all pregnant women through antenatal care. Handling and proper care are essential for premature births or babies with low birth weight to prevent death during the neonatal period.

This study shows the need to educate women of reproductive age to prepare for their first birth and plan for long-term contraceptive use, especially for mothers with high parity status. The higher the number of births, the higher the child's risk for neonatal death; a short birth interval exacerbates this condition. Therefore, the need to increase family planning services can benefit childbirth spacing, especially for women with multiparous parity status.

The reduction in neonatal morbidity and mortality will only be achieved if antenatal and post-natal care is fully integrated with medical care. Thus, persuasive action and easy access to health facilities from the government is needed so that mothers could choose a suitable place of delivery. Moreover, health programs should accelerate in directing all deliveries to be carried out at health facilities. Although the results showed that home delivery was protective against the incidence of neonatal mortality, delivery outside of healthcare facilities could not guarantee that it could provide emergency services and postpartum health monitoring for both mother and baby.

\section{REFERENCES}

Adewuyi, E.O. and Zhao, Y., 2017. Determinants of neonatal mortality in rural and urban Nigeria :Evidence from a population-based national survey. pp.190-200.

Bai, J., Wong, F.W.S., Bauman, A. and Mohsin, M., 2002. Parity and pregnancy outcomes. (February).

Gordis, L., 2014. Epidemiology. Canada: Elsevier Ltd.

Hill, K. and Choi, Y., 2006. Neonatal mortality in the developing world. Demographic Research, 14, pp.429-452.

Kesterton, A.J., Cleland, J., Sloggett, A. and Ronsmans, C., 2010. Institutional 
delivery in rural India: The relative importance of accessibility and economic status. BMC Pregnancy and Childbirth, 10.

Al Kibria, G.M., Khanam, R., Mitra, D.K., Mahmud, A., Begum, N., Moin, S.M.I., Saha, S.K. and Baqui, A., 2018. Rates and determinants of neonatal mortality in two rural subdistricts of Sylhet, Bangladesh. PLoS ONE, [online] 13(11), pp.119. Available at: $<$ http://dx.doi.org/10.1371/journal. pone.0206795>.

Malhotra, N., Puri, R., Malhotra, J. \& Singh, K. N., 2014. Operative Obstetrics \& Gynecology. s.1.:JP Medical Ltd.

Ministry of Health RI, National Population and Family Planning Agency and RISKESDAS, 2018. Demographic Survey and Basic Health Research 2018, pp.1-446.

Mosley,W,H and Chen, L, C., 2003. Extracted from: Population and Development Review 1984; 10 Suppl : 25 - 45 . Bull World Health Organ, 81(2), pp.140-145.

Muenchhoff, M. and Goulder, P.J.R., 2014. Sex differences in pediatric infectious diseases. Journal of Infectious Diseases, 209 (SUPPL. $3)$.

Oakley, L., Maconochie, N., Doyle, P., Dattani, N. and Moser, K., 2009. Multivariate analysis of infant death in England and Wales in 2005-06, with focus on socio-economic status and deprivation. Health statistics quarterly / Office for National Statistics, (42), pp.22-39.

Pongou, R., 2013. Why Is Infant Mortality Higher in Boys Than in Girls? A New Hypothesis Based on Preconception Environment and Evidence From a Large Sample of Twins. Demography, 50(2), pp.421-444.

Prawirohardjo, S., 2008. Midwifery Science. Jakarta: Bina Pustaka Foundation.

UNICEF, 2016. Maternal and Newborn Health Disparities Kenya. UNICEF, Maternal and Newborn Health Disparities, p.8.

UNICEF: WHO: World Bank: UN DESA, 2018. Levels and Trends in Child Mortality 2018. [online] pp.1-44. Available at: $<$ https://data.unicef.org/wpcontent/uploads/2018/09/UNIGME-Child-Mortality-Report2018.pdf>.

UNICEF: WHO: World Bank: UN DESA, 2019. Levels \& Trends in Child Mortality 2019. UN IGME report, p.52.

WHO, 2006. Perinatal and neonatal mortality. WHO Library Cataloguing-in-Publication Data. Geneva.

WHO, 2020. World health statistics 2020: monitoring health for the SDGs, sustainable development goals. Geneva. 